Research Paper

\title{
Digital Transformation Challenges in the Sales of Pharmaceutical Companies in Japan
}

\author{
Qinxian Liu $^{1 *}$; Yaxin Zhao'; Taro Kamioka ${ }^{1}$ and Michihiko Nakamura ${ }^{2}$ \\ ${ }^{1}$ School of Business Administration, Hitotsubashi University, Japan \\ ${ }^{2}$ Real-World \& Analytics Solutions, Strategy Office, IQVIA Solutions Japan K.K., Japan \\ *Corresponding author: bd191010@g.hit-u.ac.jp
}

\begin{abstract}
While the pharmaceutical industry is rated as having less digital maturity than other industries, the changing environment, especially due to the COVID-19 pandemic, has been giving momentum to the rise of digital transformation (DT). This study explored the current status and background of DT on sales and how DT has been promoted in Japan based on 20 interviews with leaders and consultants in the pharmaceutical industry. The results showed that while their DT was still at an early stage, DT had been driven by external factors, including the pandemic, with commitment from top management. We identified four changing external factors and nine initiatives in relation to the new activities: three in the practical stage and six in the developing stage. An interesting aspect was that regulations might both promote and hinder DT in this industry combined with COVID-19. As there has been limited domain-specific research in DT of the pharmaceutical industry in Asia, the study is considered to contribute to both academic research and practice in Asian business.
\end{abstract}

Keywords: Digital transformation, Pharmaceutical company, Sales, Government regulation, COVID-19. 


\section{Introduction}

Digital transformation (DT) is a process that integrates digital technologies to enable vital changes that contribute to entities (Vial, 2019). DT transforms businesses and organizations by strategically utilizing technology. Facing a dynamically changing environment, organizations consider it critical to maintain their competitive advantages in their industry (Hartl and Hess, 2017). Although DT has attracted wide attention from researchers and practitioners (Hanelt et al., 2015; Savastano et al., 2019; Vial, 2019), most of the research has viewed DT as a generalized phenomenon. It would also be beneficial to narrow down the research target since DT varies greatly by industry, business function, and national context (Remane et al., 2017; Gurbaxani and Dunkle, 2019; Kane et al., 2019; Soltani Delgosha et al., 2020).

The pharmaceutical industry lags behind in DT (Gurbaxani and Dunkle, 2019), even though it is a core healthcare field that is expected to reap the benefits of DT (Haggerty, 2017). However, the COVID-19 pandemic has recently given a boost to DT (Khan and Basak, 2021), with the most affected function expected to be sales (Darwish et al., 2020). In Japan, numerous medical institutions restrict salesperson visits to prevent the spread of COVID-19, thereby hindering face-to-face communication with doctors. To overcome this challenge, Japanese medical institutions have started to seek digital solutions. It is meaningful to investigate what difficulties these institutions are encountering and how they are tackling these challenges in a domain-specific condition.

This research investigated the current status of DT of sales in pharmaceutical companies and how it was being promoted in Japan. Studies of DT have rarely been conducted for the sales function (Guenzi and Habel, 2020) and are very limited in the pharmaceutical industry, as well as in the Asian region. Pharmaceutical companies in Japan were thought to be conservative and to have a negative attitude about changes in rigorous regulations (Nagatani et al., 2018). A total of 20 interviews was conducted to determine how the sales of pharmaceutical companies drive DT. This research is considered to contribute to both academic research and practice as an example of industry-, function-, and country-specific research on DT. It is also expected to contribute to academic literature to record, analyze, and organize how the transformation has been conducted during the pandemic outbreak which we might rarely experience. The rest of this study consists of a literature review, methodology, findings, conclusions and discussion, and practical implications for Asian business.

\section{Literature Review}

Vial (2019) defined DT as "a process aiming at improving an entity by triggering significant changes to its properties via combinations of information, computing, communication, and connectivity technologies" (pp. 118). Past academic research on DT in the business field might be classified into two categories: research focused on technology and on the business or organization. For example, the former investigated the technological factors in DT (Kraus et al., 2021). The latter explored strategy (Guenzi and Habel, 2020), structural changes (Earley, 2014), organizational culture (Hartl and Hess, 2017), leadership (Benlian and Haffke, 2016), and employee skills (Dremel et al., 2017). Our research is interested in the transformation of business activities in the sales function. 
DT was viewed as a generalized process in the main research stream in the aforementioned studies. However, DT is implemented differently depending on the industry, business function, and country (Remane et al., 2017; Gurbaxani and Dunkle, 2019; Kane et al., 2019; Soltani Delgosha et al., 2020). Over the past few years, domain (industry, function and country)-specific research has emerged. For example, industryspecific studies have been conducted in the creative industries ( $\mathrm{Li}, 2020$ ), manufacturing industries (Frank et al., 2019), and financial services (Chanias, 2017); country-specific research has been carried out in Central European countries (Esses et al., 2021) and Germany (Frick et al., 2021); and function-specific research has been applied to human resources (Jackson and Dunn-Jensen, 2021), innovation (Hadjielias et al., 2021), and strategic procurement operations (Altundag, 2022). As a domainspecific study, we target the sales function of the pharmaceutical industry in Japan.

The main research fields in DT of pharmaceutical companies have been drug development (Finelli and Narasimhan, 2020), supply chains (Ângelo et al., 2017), and quality of care (Laurenza et al., 2018). Research focusing on DT in sales functions in pharmaceutical companies is rare (Guenzi and Habel, 2020). Combined with the high evaluation of DT in the area of innovation (Gurbaxani and Dunkle, 2019), the function with the lowest level of digital maturity in pharmaceutical companies might be attributed to sales and marketing. Irrespective of industry, how DT is promoted in sales activities is not clear, although digital technologies are reported to have positive effects on company performance (Zhao, 2018). Most of the research was interested in implementing or exploiting specific digital tools (Wedell and Hempeck, 1987; Davis et al., 1989).

The pharmaceutical industry is a core of the healthcare ecosystem, and DT was also studied in the framework of healthcare (Agarwal et al., 2010) with hospitals (Frick et al., 2021). DT was expected to have positive impacts on healthcare as a whole (Haggerty, 2017; Kraus et al., 2021). According to the review of DT on healthcare (Kraus et al., 2021), existing research has discussed operational efficiency by health care providers, patient-centered approaches, organizational factors and managerial implications, workforce practices, and socioeconomic aspects.

When applying DT in a specific industry, we should pay much attention to industry regulations. According to Breidbach et al. (2020), regulations in the financial industry, which were as strict as those in the pharmaceutical industry, had a two-sided effect of both promoting and hindering the introduction of fintech. Gopal et al. (2019) pointed out that regulations in the pharmaceutical industry impeded the efficient usage of health information. However, since regulations depend on the specific country, the impacts may not be easily determined. Regulations for the pharmaceutical industry in Japan are strictly formulated in the "Guidelines for Sales Information Provision Activities for Drugs"(Ministry of Health, Labour and Welfare, 2018). For instance, salespeople in pharmaceutical companies are generally termed medicine representatives (MRs), who must provide precise information regarding the company's drugs to medical professionals or customers (e.g., doctors and pharmacists at hospitals and clinics). In addition, they are not allowed to sell drugs directly to customers or patients.

In relation to DT, a recent remarkable environmental factor was the COVID-19 pandemic. The pandemic stimulated the digitalization of customer relationships (Kim, 2020). In the retail business, omnichannel sales have been a hot topic not only in B2C 
but also in B2B business (Angevine et al., 2021; Gavin et al., 2020). Data-driven marketing and sales would be the next normal (Bibby et al., 2021). The domain-specific influences on DT should now be analyzed.

To the best of our knowledge, there is no research on DT focusing on the sales function in the pharmaceutical industry. Nor is there research on DT in the combined context of stiff regulations and the pandemic situation. In-depth analysis should be conducted to identify what should be considered in the process of DT in the sales of pharmaceutical companies during the COVID-19 outbreak in Japan.

\section{Methodology}

Since the pharmaceutical industry in Japan was assumed to be at an early stage of DT with scarce literature, our explorative research adopted semi-structured interviews with leaders in the companies practically realizing DT to collect data about how DT was promoted with an open mind (Myers and Newman, 2007).

\section{Preliminary Interview}

First, we conducted 8 preliminary interviews in May 2020 to obtain a comprehensive view of the DT in sales of pharmaceutical companies in Japan and to decide on sampling and the questionnaire to be applied in the subsequent main interview. The respondents were expected to have an overall understanding of pharmaceutical companies.

- One CDO (Chief Digital Officer) (R1) and one MR leader of a pharmaceutical company

- One researcher studying pharmaceutical industry policies in a research institute (R2)

- Two consultants for the pharmaceutical industry and three staff members in charge of MR contact in a solution service company

In this preliminary interview, we confirmed that they perceived that the sales function was in the early stage of DT, for example:

"Pharmaceutical companies have been lagging behind other industries in digital progress to some extent, especially on the sales and marketing side." (R2)

"Our research and development function had taken advantage of data since before, and now leverages AI, but not in sales and other functions." (R1)

This perception was consistent with research outside Japan (Remane et al., 2017; Gurbaxani and Dunkle, 2019). The low level of digital maturity in this industry was considered to be influenced by common factors, so we were careful with the external factors in the main interview.

On the other hand, most respondents suspected that there were large gaps in DT between companies in the planning stages and those in the implementation stages. To collect more meaningful data on what truly happened in relation to DT, we were careful to choose companies with a certain amount of DT experience to include in the sample of firms in the main interview. 


\section{Sampling}

Based on the preliminary interview, supposing that companies with higher sales performance could advance more in sales of DT (Barann et al., 2019), we targeted our sample on the top 20 companies in medicine sales revenue in Japan in 2019 or companies that had the top 10 sales performance of a specific type of medicine. We tried to contact those target companies, and 6 companies responded and participated in the main interview (Table 1). Companies A, B, C and D were major Japanese pharmaceutical companies. Companies $\mathrm{E}$ and $\mathrm{F}$ were foreign-owned companies, but the management and business operations of Company $\mathrm{E}$ were independent of the owner.

An author who had been involved in consulting for the pharmaceutical industry for more than 15 years arranged for appropriate interviewees. Two types of interviewees were selected from each company, so a total of 12 interviews were conducted from September to November 2020. All of the X1-type interviewees had experiences in IT/digital or sales more than 20 years, and were supposed to provide information on those factors likely to boost or hinder DT, as well as on their current status and achievements. The other interviewee type, labeled X2 (e.g., A2, B2), was the general manager- or director-level position and familiar with real sales activities and promoting digital solutions to business (e.g., sales promotion headquarters). All of the X2-type interviewees had worked in this industry more than 10 years and were involved in sales with digital more than 3 years, so that they were expected to answer effectively questions regarding the use of digital technologies in practical applications.

Table 1: Information of Respondents

\begin{tabular}{|c|c|c|c|}
\hline Company & Type of the Company & Respondent & Short Profile \\
\hline \multirow[t]{2}{*}{ Company A } & $\begin{array}{l}\text { Domestic; } \\
\text { In the top } 5 \text { medicine sales } \\
\text { in Japan; } \\
\text { Exploiting digital } \\
\text { technologies in sales }\end{array}$ & A1 & $\begin{array}{l}\text { E-Communication; } \\
\text { Promotion/ Sales Planning } \\
\text { Officer; } \\
\text { Over } 20 \text { years of sales in } \\
\text { pharma }\end{array}$ \\
\hline & & A2 & $\begin{array}{l}\text { Director; Information } \\
\text { Analysis; } \\
\text { Over } 10 \text { years of sales in } \\
\text { pharma }\end{array}$ \\
\hline \multirow[t]{2}{*}{ Company B } & $\begin{array}{l}\text { Domestic; } \\
\text { In the top } 10 \text { medicine sales } \\
\text { in Japan; } \\
\text { Exploiting digital } \\
\text { technologies in sales; } \\
\text { A clear digital strategy }\end{array}$ & B1 & $\begin{array}{l}\text { CDO; Marketing, } \\
\text { Technology, Strategy } \\
\text { Promotion Officer; } \\
\text { Over } 20 \text { years of } \\
\text { sales/IT/digital/marketing in } \\
\text { pharma }\end{array}$ \\
\hline & & B2 & $\begin{array}{l}\text { Director in Frontier } \\
\text { Business Promotion; } \\
\text { Over } 10 \text { years of sales in } \\
\text { pharma }\end{array}$ \\
\hline Company C & $\begin{array}{l}\text { Domestic; } \\
\text { In the top } 5 \text { medicine sales } \\
\text { in Japan; }\end{array}$ & $\mathrm{C} 1$ & $\begin{array}{l}\text { Senior Managing Executive } \\
\text { Officer in DT Promotion; } \\
\text { Over } 20 \text { years of } \\
\text { R\&D/digital in pharma }\end{array}$ \\
\hline
\end{tabular}




\begin{tabular}{|c|c|c|c|}
\hline Company & Type of the Company & Respondent & Short Profile \\
\hline \multirow[b]{2}{*}{ Company D } & $\begin{array}{l}\text { Exploiting digital } \\
\text { technologies in sales; } \\
\text { A clear digital strategy }\end{array}$ & $\mathrm{C} 2$ & $\begin{array}{l}\text { General Manager in Digital } \\
\text { Planning; } \\
\text { Over } 10 \text { years of sales in } \\
\text { pharma }\end{array}$ \\
\hline & $\begin{array}{l}\text { Domestic; } \\
\text { In the top } 15 \text { medicine sales } \\
\text { in Japan; } \\
\text { Exploiting digital } \\
\text { technologies in sales }\end{array}$ & D1 & $\begin{array}{l}\text { Executive Officer in } \\
\text { Marketing and Sales; } \\
\text { Over } 20 \text { years of } \\
\text { marketing/sales in pharma } \\
\text { General Manager; Sales } \\
\text { Planning; } \\
\text { Over } 10 \text { years of sales in } \\
\text { pharma }\end{array}$ \\
\hline \multirow[t]{2}{*}{ Company E } & $\begin{array}{l}\text { Foreign-owned with } \\
\text { independent management; } \\
\text { In the top } 5 \text { medicine sales } \\
\text { in Japan and the top } 3 \text { sales } \\
\text { of a specific medicine type; }\end{array}$ & E1 & $\begin{array}{l}\text { CDO; Digital and IT } \\
\text { Management; } \\
\text { Over } 20 \text { years of sales and } \\
\text { consulting in an IT } \\
\text { company }\end{array}$ \\
\hline & $\begin{array}{l}\text { Exploiting digital } \\
\text { technologies in sales }\end{array}$ & E2 & $\begin{array}{l}\text { General Manager; Digital } \\
\text { Planning; } \\
\text { Over } 10 \text { years of sales in } \\
\text { pharma }\end{array}$ \\
\hline Company F & $\begin{array}{l}\text { Foreign-owned with no } \\
\text { R\&D in Japan; } \\
\text { In the top sales of a specific } \\
\text { medicine type; } \\
\text { Exploiting digital } \\
\text { technologies in sales }\end{array}$ & $\mathrm{F} 1$ & $\begin{array}{l}\text { Executive Officer in } \\
\text { Customer \& Strategy Sales; } \\
\text { Over } 20 \text { years of } \\
\text { marketing/digital/data in a } \\
\text { consulting company and } 5 \\
\text { years in pharma }\end{array}$ \\
\hline & & F2 & $\begin{array}{l}\text { Manager; Customer } \\
\text { Experience Management; } \\
\text { Over } 10 \text { years of sales in } \\
\text { pharma }\end{array}$ \\
\hline
\end{tabular}

\section{Data Collection}

We conducted interviews with semi-structured, open-ended questions about what factors promoted or hindered DT and how business activities were transformed through DT. All interviews were held for 1 to 2 hours on Zoom. More time was spent with X1type respondents with questions from the perspective of strategy, resources, and evaluation of DT and with X2-type respondents from the perspective of what changes and problems were happening in their daily work through the use of digital technology.

\section{Data Analysis}

For an in-depth analysis of the results, all interviews were recorded and then transcribed. The transcripts were rigorously processed, and similar statements were clustered by using NVivo 12. First, open coding was conducted, and the codes and descriptions were then discussed among authors with the support of one of the consultants in the preliminary interviews. Tentatively, 137 descriptive concepts were summarized. After removing the concepts that were irrelevant to sales, 72 concepts were verified and connected with each other into subordinate and general dimensions. In this step, this study discussed the mentioned concepts and referenced previous academic research. Last, the concepts were grouped into three categories: external factors, top management 
commitment, and new activities and challenges.

\section{Findings}

The findings were summarized in Figure 1. "New Activities and Challenges" were led by the "Top Management Commitment" and influenced by "External Factors that Drive DT".

\section{External Factors that Drive DT}

The following four factors were identified as drivers of DT in the sales of pharmaceutical companies. They express the reasons why sales of pharmaceutical companies started to boost DT.

\section{Emergence of new digital technology}

DT promotion was stimulated by emerging digital technologies, as seen in other industries (Frank et al., 2019). The interviewed companies that were proceeding with DT were active in not only adopting but also utilizing the technologies. They expected to adapt to a changing technology environment (Chan et al., 2018).

"New digital technologies are emerging constantly. I consider that artificial intelligence most significantly impacts our industry ... I suppose that the technology for visualization of various data is critical to our business ... the significance of existence of sales was raised ... I consider the sales should be transformed so that MRs should use technologies in a way that can yield business outcomes." (B1)

"In the context of Society 5.0 proposed by the government, a wide variety of data is increasing significantly ... Companies expect digital technology to support new business transformation by utilizing data, which is an urgent issue." (C1)

\section{Prediction of the decline in sales and profits}

Most of the interviewees remarked on the prediction that sales and profits would decline as the background of DT. Japan is facing the problem of aging with a decreasing population, and increasing national medical costs have led the government to try to keep pharmaceutical prices down (Umekawa, 2019). In addition, the cost of developing new drugs has been increasing. Against the background of restructuring their salesforce, pharmaceutical companies were inevitably turning to the use of digital technologies.

"The pharmaceutical industry is facing a difficult external environment, especially with the price of medicines plummeting, and the future figures are very challenging. Thus, the scale (numbers of MR) cannot be maintained as in the past. It should be reduced in the future, when considering how to maintain at least the same amount of work with less workforce, we think about shifting to digital." (B1) 
Figure 1: Digital Transformation Challenges in the Sales of Pharmaceutical Companies in Japan

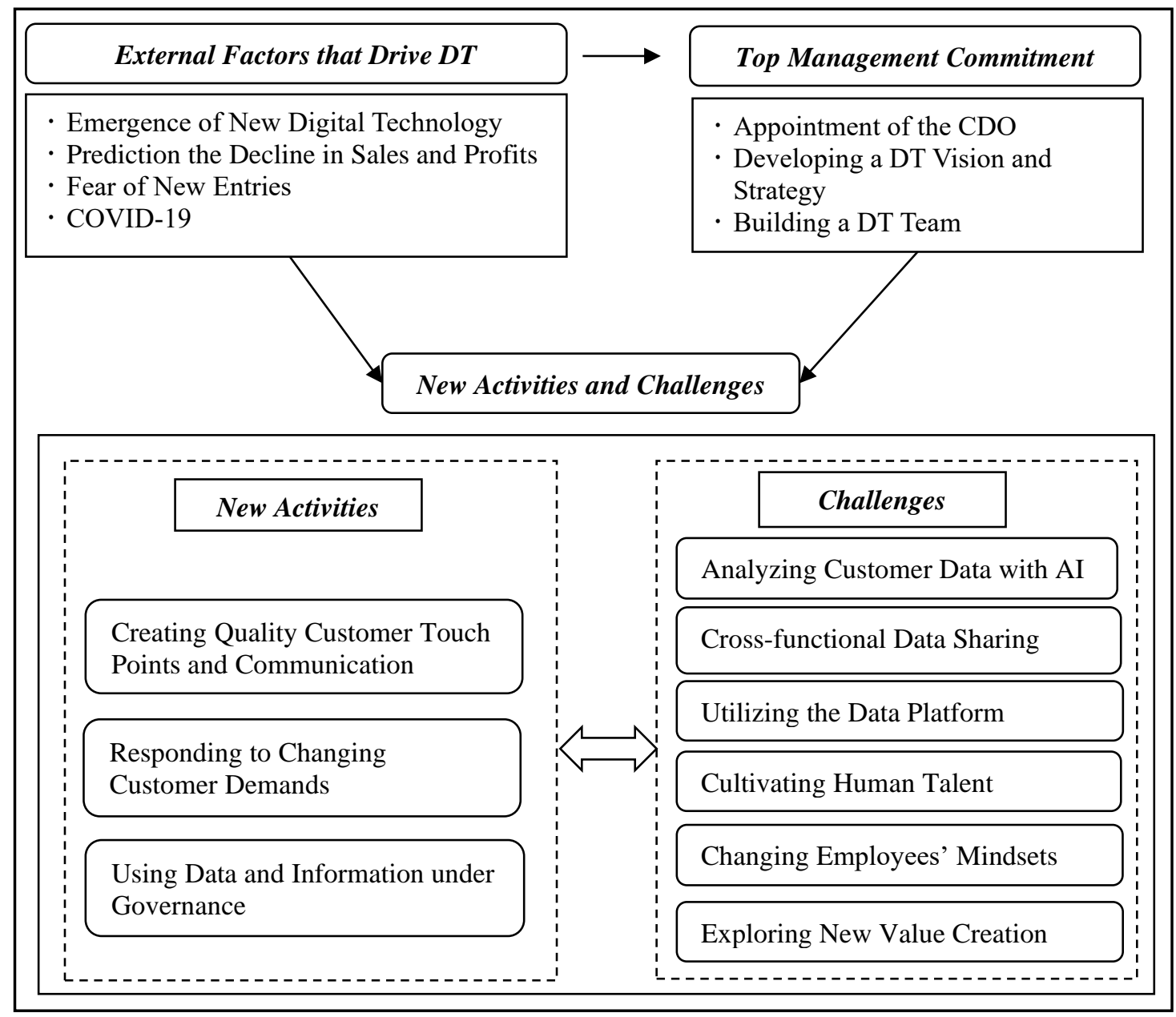

\section{Fear of new entries}

The pharmaceutical companies were aware of competitors from other industries in the healthcare field (e.g., companies in IT, food, fitness), and were afraid of disruption of their business, as had happened with taxi companies.

"Amazon has already acquired a healthcare company in America. Moreover, Apple collaborates with hospitals to process healthcare data ... Competitors like those are scary when they are considering entering the pharmaceutical business. They have crushed many other industries, and you may feel that it is likely to be crushed by them." (B1)

To protect themselves from the competition, pharmaceutical companies were considering entering other healthcare sectors, for example, disease prevention (B1), as in the subsection "Exploring New Value Creation". 


\section{COVID-19}

Direct access to customers or doctors on sales activities was becoming difficult with the regulations in Japan (Nagatani et al., 2018), and such restrictions were more severe during the COVID-19 pandemic. A growing number of hospitals and healthcare facilities announced visit restrictions, thereby causing MRs to face more difficulties in accessing their customers face to face, which had been the main communication method.

"Not only our company but also all pharmaceutical companies have been affected by COVID-19, and due to visit restrictions, we are not able to provide information to doctors as much as we would like." (A1)

Most of the respondents agreed that the situation accelerated the use of digital communication tools such as E-detailing programs or web seminars.

\section{Top Management Commitment}

In response to external factors, the top management teams recognized that DT was a top priority and demonstrated a clear commitment to DT at the corporate level, which was critical in driving the transformation.

\section{Appointment of the $\mathrm{CDO}$}

The pharmaceutical companies tended to appoint an executive leader responsible for implementing and accelerating DT, typically the CDO (Chief Digital Officer), who was backed up by the top management team. Companies B and $\mathrm{E}$ formally adopted CDOs (B1, E1), and the executive of Company C (C1) worked as the CDO. Executive leaders were expected to plan and deploy digital transformation strategies (Horlacher and Hess, 2016), and the transformation in sales and marketing was one of their top priorities (B1). The conflict between the leadership of digital IT and that of traditional IT was an issue in promoting DT (B1). Company $\mathrm{C}$ emphasized the relationship and synergetic effect among the DT, Data, and IT divisions so that the senior executive officer (C1) was positioned in charge of three divisions.

\section{Developing a DT vision and strategy}

The CDO and top management team presented the DT initiatives and strategies. Companies B and E stipulated the digital vision in their corporate midterm management plan:

"According to our fourth midterm management plan, the digital vision and DT strategies are clearly stated and correlated tightly with other strategies, e.g., exploration of new business, globalization strategy. And taking advantage of digital technologies are regarded as the foundation for future innovation." (B1)

\section{Building a DT team}

A DT team was organized to carry out DT, typically under the direction of the CDO. They were leading in breaking silos $(\mathrm{C} 1)$, planning the DT roadmap (C2), identifying problems (B1, D1), and propelling the implementation of digital tools (B1, D1). They 
were also trying to change the mindset of employees by sharing best practices (F1) and promoting collaboration among divisions or teams.

"First, sales teams in the business division and the DT team worked together to determine the cause of a problem in existing operational processes. I supported that they collaborated to implement new technologies and data analytics ... Later, I am so happy to feel that their relationships have changed after the implementation, since they are more proactive to communicate with each other." (B1)

\section{New Activities and Challenges}

We identified the following nine initiatives as new activities and challenges related to DT of the sales of pharmaceutical companies. They were all in process, whereas they fell into two groups based on the progress assessed with industry experts. The first three activities were comparatively developed on a practical level: "Creating Quality Customer Touch Points and Communication", "Responding to Changing Customer Demands", and "Using Data and Information under Governance". Much of them could be solved within the sales function with the help of the CDO and DT team. The other six activities were just beginning or in the experimental stage: "Analyzing Customer Data with AI", "Cross-functional Data Sharing", "Utilizing the Data Platform", "Cultivating Human Talent", "Changing Employees' Mindsets", and "Exploring New Value Creation". They should be approached from a corporate-wide perspective.

\section{Creating quality customer touch points and communication}

As previously described, the COVID-19 pandemic and government regulations caused medical institutions to restrict MR visits to doctors. The sales departments shifted to the use of full-scale digital communication channels with customers, including web seminars, E-detailing, and social network services (SNS). They were more concerned about improving the quality and efficiency of communication in the new touchpoints than simply increasing the number of channels:

"We adopted the most popular SNS as a new touchpoint with doctors. We think it better fits their habits." (E2)

"...We expect the use of digital technologies to improve the quality of communication and the efficiency of the value chain." (E1)

There were various approaches to using those touchpoints. For example, while Company E emphasized providing the identical message to customers across multiple channels, Company F adopted an omnichannel approach (DeSalles, 2015) and used each of the channels differently:

"I would like to be able to orchestrate the use of the various omnichannels. For instance, we initially deliver a flash report to doctors via e-mail, subsequently make a face-to-face discussion with them about it in depth, exchange several email messages, and finally close it face-to-face." (F2) 
Moreover, enhancing MRs' communication skills was of increasing importance. The communication skill was highlighted more to be able to draw upon digital power. For instance:

"In the past, the MRs' interviewing skills were good enough to get correct data (on a face-to-face basis). However, it has been changed after COVID-19... Some MRs could not finish the questionnaire that aims to acquire doctors' information (in the digital environment)." (A2)

\section{Responding to changing customer demands}

Doctors used to passively select from the information and knowledge regarding medicine prepared by MRs. However, younger doctors were getting used to numerous digital communication tools, and they proactively attempted to search for medical information themselves. There was also a case in which an MR helped an elderly doctor unfamiliar with but interested in wireless communication build a Wi-Fi environment in the clinic (Company B).

Moreover, the interviewees largely highlighted that visit restrictions by MRs during the COVID-19 outbreak might trigger their proactive behavior. For example, the number of communications initiated by doctors rather than MRs increased (B1). Pharmaceutical companies felt the need to respond to changing customers. Some of them were advancing the automation of customer contact centers with chatbots and RPA.

"The implementation of chatbots has already allowed doctors to make reservations (with MRs), and the repeat rate is $80 \%$, thereby demonstrating that doctors are highly satisfied, and we are considering releasing other digital channels by VR." (B1)

However, the sales function was aware that not all doctors would accept the digital channel. Whether to contact a doctor in digital ways or face to face was determined by the doctor (B1). While the preference might be related to a variety of factors, such as the doctor's age (Company F) and attributes of the clinics (Company D), MRs should review the customer history data before visiting doctors.

\section{Using data and information under governance}

Pharmaceutical companies were required to ensure the veracity of the information on drugs to inform doctors since incorrect information might cause life-threatening accidents. All the interviewed companies built the data governance (Abraham et al., 2019) that MRs were obliged to follow when they showed information and data to doctors. The digital content that MRs could use was generally prepared, and whether MRs communicated in accordance with the guidelines was monitored by the companies.

"What you showed on the iPad is recorded, including what types of information you provided. The company checks to see if you have provided the correct information." (E2)

Moreover, they were required to submit their daily report on what had been communicated and what happened with the doctors (Company E). The activities were 
traditionally supervised by line managers, but now, some companies were going to replace this labor with AI, for example, which automatically verified the use of prohibited words on daily reports (Company D).

\section{Analyzing customer data with AI}

The pharmaceutical companies were attempting data analysis more aggressively with AI in addition to conventional methodologies. AI data analysis started in the R\&D process (e.g., drug development and clinical trials) and extended to marketing and sales. For instance, when and how MR should visit and talk with doctors was optimized in accordance with the data analysis:

"Given the information acquired from the former customer visit records, the AI system recommends the best routine of visits to doctors ... The situation has changed due to COVID-19 ... We should always be adjusting the system." (F2)

A major challenge was data quality. Currently, sales teams have developed an interest in applying AI to an in-depth qualitative data analysis (Companies A, B, E); however, most of the data input by MRs and doctors could not satisfy the AI requirements to function effectively, thereby requiring massive data cleansing. Company $\mathrm{C}$ emphasized the importance of consolidating data engineering processes and was actively hiring data engineers.

\section{Cross-functional data sharing}

The value of sharing data for reaping the benefits of big data and analytics was recognized, but the scope of sharing was different among the companies. While Company F, a global company that was advanced in corporate-wide data and knowledge sharing, the others had not reached that point. It was often the case that sales teams independently adopted those tools, such as CRM and business intelligence (A2, E2), so that most of the data sharing that took place was within the sales teams, not cross-functional or divisional. Some of them were aiming to realize it on a data platform described later (Company C, E):

"Since the information for MRs was distributed in various systems, I had to go to check each one separately. Therefore, we needed to establish a data management platform to store and use the data in one place." (E2)

In the meantime, data sharing cannot be achieved only through technological transformation. It was also recognized as a matter of transforming the organizational process. Company $\mathrm{C}$ was in the process of establishing the process for data sharing under data governance and guidelines. Company $\mathrm{D}$ adopted an interesting process regarding the decision-making of what data should be shared, through a mixture of topdown and bottom-up approaches:

"Information was rated for sharing by both the head office side and the frontline MRs. If the head office thought the information was valid, we gave many stars ... And if the field thought the information was valid, we could press the 'nice' button." (D2) 
To facilitate cross-functional sharing, the cultural transformation was mentioned (Company C), although organizational culture could not be changed in the short term.

\section{Utilizing the data platform}

From a strategic viewpoint, AI and big data were repeatedly mentioned in our interviews. Most of the companies introduced a data platform to provide an integrated environment to realize corporate-wide "cross-functional data sharing". A data platform was considered to integrate the data, process the data, help the company mentor business teams, and facilitate business growth ( $\mathrm{Li}$ et al., 2018). In pharmaceutical companies, the R\&D function was the first to adopt data sharing, and the sales function was seeking an effective way to use it.

"In recent years, there has been an increasing need to combine and analyze various data ... So we are trying to analyze clinically and related data in a complex manner. It is a gradual process, and I'm trying to remodel it into a platform that can be used in this kind of sales and marketing area... I'm wondering how to make it while grasping the needs of the sales department." (A1)

One of the limited cases of cross-functional data sharing with the sales function was as follows:

"Salespeople can access data on products and clinical trials generated by $R \& D$ teams. They can use the data to explain some probabilities of side effects about a drug to doctors." (C1)

In addition to corporate-wide data sharing, integrating internal and external data would also be of importance. For sales and marketing teams to generate valuable insights, the combination of various data may provide new perspectives on customers on the platform. Company A was planning to combine its sales and marketing data with the market environment and competition.

\section{Cultivating human talent}

The cultivation of human talent for DT was considered a challenge for all companies. The talent shortage was so critical that they were more active in recruiting talent than ever. They also offered internal training programs or employee programs offered by educational institutes. The strategic focus was on data science and the fusion between business and technology (E1), but the talent gap between what was ideal and reality was observed.

"To relieve the shortage, an approach is to train employees interested in emerging digital technologies, and the other approach involves recruitment. Data scientists were recruited from other industries to address the problem at hand ... We need the talent familiar with technology and business to cultivate." (F2)

The training program covered various skills from digital literacy to data analysis, AI programming, design thinking, and user experience design (E1). However, they found difficulty in designing the programs due to huge individual differences in skills, and the skill sets were hard to define for the respective skill level, which led to dissatisfaction 
with training efforts (Spritzer et al., 2017). On the whole, a trial-and-error approach was adopted.

In addition, there was a case of exploiting digital technology in employee education. Company B adopted VR and mixed reality technologies in their educational system, so the effect of drugs on the human body would be more easily understood threedimensionally in a time sequence:

"The learning effect was 2.6 times by exploiting virtual or mixed reality compared with movies on a PC or iPad." (B1)

\section{Changing employees' mindsets}

In relation to human talent and skills, pharmaceutical companies were aware that changing MR mindsets was significant for moving forward with DT.

"Changing their mindsets and utilizing data strategically are my first priorities as the CDO." (B1)

Although there was some resistance to adopting digital technologies among the elderly generation of employees (F2), it might not be so substantial (E1, F1). Employees' inertia and lack of a sense of urgency might hinder the transformation more seriously:

"I think you have less resistance, but you still have people who are very much tied to the old ways of doing things." (F1)

"I am aware that we would not use digital technology in the future without a sense of urgency." (A1)

E1 emphasized a test-and-learn mindset to learn from experience and failure. F1 mentioned the concept of growth mindsets, which described the underlying beliefs that people have about learning and intelligence (Dweck, 2016). Cultivating the growth mindset was expected to help overcome the resistance and inertia in MRs. In addition, the synergy between digital skills and mindsets was also mentioned (F1, B1). There might be good chemistry between them. Digital dexterity refers to "a set of beliefs, mindsets and behaviors that help employees deliver faster and more valuable outcomes from digital initiatives" (Gartner, 2018, pp. 5). It described the ability and ambition of using digital technologies.

"The concept of digital dexterity by Gartner is very important. The ability to apply digital technology to business is essential. In addition, ambition is also needed to be developed. If we can achieve ability and ambition at the same time, the DT process will be smooth. To acquire abilities, a strong ambition is crucial at first." (B1)

\section{Exploring new value creation}

The pharmaceutical companies were aware that only exploiting the extant business and resources was insufficient in competitive and changing environments. They were exploring opportunities for new value creation, although most of the challenges were in the stage of proof of concept. An example was as follows: 
"We are experimenting with VR devices for business. For instance, doctors should be offered a more realistic scenario so that they can understand the efficacy of medicines, as well as the process of patient recovery. They are likely to gain insight into how to prescribe it." (B1)

All the companies were concerned with the idea of patient centricity, which can be described as "integrated measures for listening to and partnering with patients, and placing patient well-being at the core of all initiatives" (du Plessis et al., 2017, pp. 461). In addition, Companies B, C and D attempted to develop digital therapeutics or applications to collect patient data. They were aware that they should shift to a more service-oriented approach from a pure product-oriented approach of manufacturers. However, considerable challenges were imposed by hurdles such as privacy concerns, regulations, and data quality $(\mathrm{B} 2, \mathrm{C} 1)$.

\section{Conclusions and Discussion}

This study explored how DT in the sales of pharmaceutical companies was promoted in Japan based on a total of 20 interviews. Although their DT remained in the early stage, it was driven by awareness of the changing environment with commitment from top management (Singh and Hess, 2017; Guenzi and Habel, 2020). We identified four environmental factors to influence DT and nine DT initiatives in relation to new activities that the executives and managers were concerned about.

The four environmental factors were "Emergence of New Digital Technology" (Chan et al., 2018), "Prediction of the Decline in Sales and Profit", "Fear of New Entries" (Vial, 2019), and "COVID-19" (Khan and Basak, 2021). While the first factor was similarly found in other industries, the others had an interdependent impact on regulations in a domain-specific way. An example was that the regulations might produce both side effects: promoting and hindering DT in pharmaceutical companies, combined with COVID-19. Hospitals reinforced direct contact restrictions through regulations during the COVID-19 outbreak. As a countermeasure, pharmaceutical companies accelerated the development of digital communication channels with doctors. To tackle the increased volume of data, some of the companies consolidated data governance, aiming at diffusing data use at scale.

The nine DT initiatives were classified into two groups. One was related mainly to communication with customers and was implemented at the practical level in the short term: "Creating Quality Customer Touch Points and Communication" (DeSalles, 2015), "Responding to Changing Customer Demands" (Kim, 2020), and "Using Data and Information under Governance". The other was related to more organizational foundations responding to DT and being consolidated in the longer term: "Analyzing Customer Data with AI" (DeSalles, 2015), "Cross-functional Data Sharing" (Gopal et al., 2019), "Utilizing the Data Platform" (Li et al., 2018), "Cultivating Human Talent" (Spritzer et al., 2017), "Changing Employees' Mindsets” (Dweck, 2016), and "Exploring New Value Creation" (du Plessis et al., 2017). The nine initiatives were seen in other industries, but domain-specific features were also observed by the interviewees. The omnichannel aims to provide seamless and effortless, high-quality customer experiences in contact channels (DeSalles, 2015). While in retail business, omnichannel was introduced as a distribution channel, in the pharmaceutical industry it was mainly applied 
in the communication channel to exchange medical information and knowledge.

To the best of our knowledge, there has been no research on DT in the sales area of pharmaceutical companies in Japan, so the present paper is considered to make theoretical and practical contributions. This paper presents a framework on how DT is promoted in this domain. The nine clarified initiatives provide suggestions to management about what to do in their DT implementation.

The current study has some limitations. For instance, this study selected only two types of respondents from six companies to participate in the main interview. The preliminary interview suggested that there were large gaps in DT maturity level between companies in the planning stages and those in the implementation stages. Since the population of early adopters was estimated to be small, it was thought to gain meaningful insights about companies in the early stages of DT. However, considering that DT impacts sales staff differently, more comprehensive interviews with larger samples are required. In addition, as the DT in pharmaceutical companies in Japan is at the early stage and it is expected that the circumstances will change post-COVID-19, long-term research is necessary.

Subsequent studies could propose a digital maturity model for the sales areas of pharmaceutical companies. The maturity model guides companies to achieve their transformations (Berghaus and Back, 2016), acting as a tool to help them gain insights into the existing situation and develop a possible development path for different corporate competences (Becker et al., 2009). The findings of the existing research are expected to be utilized to build a digital maturity model in the pharmaceutical industry.

\section{Implications for Asian Business}

This study presented the current status and background of DT in the sales field of pharmaceutical companies in Japan. While DT has attracted wide academic attention, research efforts in country-, industry-, or function-specific analyses are rare. That was also prominent in Asian business research.

The Asian pharmaceutical market is growing rapidly, and Japan is the second-largest market in the world (Bhaksar, 2021). There is no doubt that utilizing digital technologies in the sales and marketing field is crucial in the pharmaceutical industry in Asia. Nevertheless, there has been limited research on the application of digital technologies in the pharmaceutical industry (Ngamvichaikit, 2021), and to the best of our knowledge, no research has focused on the transformation of sales of pharmaceutical companies. In such circumstances, the current research in Japan is considered to provide a useful comprehensive view of DT for Asian business research. From the viewpoint of Asian countries or businesses, our study has at least the following two implications.

First, COVID-19 is considered to be a trigger for greater DT efforts in Asian countries. The pandemic boosted DT globally (Khan and Basak, 2021), but it might be more critical in the case of Asian businesses. Digital technology in and of itself is standardized globally, and the transformation of businesses and organizations by digital technologies is influenced by culture (Hartl and Hess, 2017). Top-down initiatives were emphasized as a necessary approach to DT (Kane et al., 2019). Nevertheless, Asian or 
Eastern culture has typically been collectivistic and bottom-up oriented (Schein, 2016), with strong top-down approaches not as applicable as in Western countries. Ironically, the pandemic was considered to have prompted Asian leaders to more readily adopt top-down approaches. The mindset of employees was considered to have become more flexible in accepting the transformation during the pandemic emergency, even though they usually worked through inertia and resisted DT. As stated by B1 and E1, the situation in which the conventional way could no longer work became a good reason or excuse to fundamentally change the company by utilizing digital technologies. The outbreak might trigger MRs' proactive behavior in utilizing digital tools to maintain their performance. In particular, top management in Asia should take advantage of the opportunity to transform firms more strategically.

Second, our study shows that domain-specific factors should be deliberately taken into account when considering the relationship between regulation and DT. Our study suggested that the conflicting results demonstrated in past research (Gopal et al., 2019; Breidbach et al., 2020) might be attributed to country-specific conditions. Since regulations are different among countries, the effects should depend on country-specific factors. The regulations in Japan seemed to be more severe in the "Guidelines for Sales Information Provision Activities for Drugs" (2018). As described above, regulations had direct and indirect impacts on the promotion of DT, in both positive and negative ways, and furthermore depended on domain-specific conditions. Considering that most DT research targeted Western countries (Kraus et al., 2021), the current paper targeted Japan to provide valuable insights for Asian business leaders.

\section{Acknowledge}

Thanks to IQVIA Solutions Japan K.K. for supporting this research. And thanks to all the members from IQVIA for helping arrange the interviews.

\section{References}

Abraham, R., Schneider, J. and vom Brocke, J, (2019), "Data governance: A conceptual framework, structured review, and research agenda", International Journal of Information Management, vol. 49, pp. 424-438.

Agarwal, R., Gao, G.G., DesRoches, C. and Jha, A.K., (2010), "The digital transformation of healthcare: Current status and the road ahead", Information Systems Research, vol. 21, no. 4 , pp. $796-809$.

Altundag, A., (2022), "A New Model for the Digital Transformation of the Strategic Procurement Function: A Case Study From the Aviation Industry", Handbook of Research on Digital Transformation, Industry Use Cases, and the Impact of Disruptive Technologies, IGI Global, pp. 92-116.

Ângelo, A., Barata, J., da Cunha, P.R. and Almeida, V., (2017), "Digital transformation in the pharmaceutical compounds supply chain: Design of a service ecosystem with elabeling”, Lecture Notes in Business Information Processing, vol. 299, pp. 307-323.

Angevine, C., Keomany, J., Thomsen, J. and Zemmel, R., (2021), "Implementing a digital transformation at industrial companies". Available at https://www.mckinsey.com/industries/advanced-electronics/ourinsights/implementing-a-digital-transformation-at-industrial-companies. 
Barann, B., Hermann, A., Cordes, A.-K., Chasin, F., Becker, J. and De, B., (2019), "Supporting Digital Transformation in Small and Medium-sized Enterprises: A Procedure Model Involving Publicly Funded Support Units", in Proceedings of the 52nd Hawaii International Conference on System Sciences, pp. 4977-4986.

Becker, J., Knackstedt, R. and Pöppelbuß, J. (2009), (2009), "Developing Maturity Models for IT Management", Business \& Information Systems Engineering, vol. 1, no. 3, pp. 213222.

Benlian, A. and Haffke, I., (2016), "Does mutuality matter? Examining the bilateral nature and effects of CEO-CIO mutual understanding”, Journal of Strategic Information Systems, vol. 25, no. 2, pp. 104-126.

Berghaus, S. and Back, A., (2016), "Stages in Digital Business Transformation: Results of an Empirical Maturity Study", in Proceedings of Tenth Mediterranean Conference on Information Systems, no. 22.

Bhaksar, H.C., (2021), "The exponential growth potential of Asia's pharmaceutical markets", Biospectrum. Available at https://www.biospectrumasia.com/opinion/25/18726/theexponential-growth-potential-of-asias-pharmaceutical-markets.html.

Bibby, C., Gordon, J., Schuler, G. and Stein, E., (2021), "The big reset: Data-driven marketing in the next normal". Available at https://www.mckinsey.com/businessfunctions/marketing-and-sales/our-insights/the-big-reset-data-driven-marketing-inthe-next-normal.

Breidbach, C.F., Keating, B.W. and Lim, C., (2020), "Fintech: research directions to explore the digital transformation of financial service systems", Journal of Service Theory and Practice, vol. 30, no. 1, pp. 79-102.

Chan, R., Nishikawa, Y., Overbeeke, J. van and Raviscioni, M., (2018), “The digital imperative for pharma companies in Japan". Available at https://www.mckinsey.com/industries/life-sciences/our-insights/the-digitalimperative-for-pharma-companies-in-japan.

Chanias, S., (2017), "Mastering digital transformation: the path of a financial services provider towards a digital transformation strategy", in Proceedings of European Conference of Information Systems, Guimaraes, Portugal, pp. 16-31.

Darwish, S., Ahmed, U. and Pahi, M.H., (2020), "Innovative work behavior during COVID-19 for medical representative in the pharmaceutical industry: Test of a moderation model in Bahrain", International Journal of Pharmaceutical Research, vol.12, no. 4, pp. 1927-1934.

Davis, F.D., Bagozzi, R.P. and Warsha, P.R., (1989), "User Acceptance of Computer Technology: A Comparison of Two Theoretical Models", Management Science, vol. 35, no. 8, pp. 982-1003.

DeSalles, M., (2015), "Moving from Multi-Channel to Omni-Channel Customer Engagement: Intelligent Interaction Analytics Are the Foundation". Available at https://www.customercontactmindxchange.com/moving-multi-channel-omni-channelcustomer-engagement.

Dremel, C., Herterich, M., Wulf, J., Waizmann, J.-C. and Brenner, W., (2017), "How AUDI AG Established Big Data Analytics in its Digital Transformation", MIS Quarterly Executive, vol. 16, pp. 81-100.

Dweck, C., (2016), "What having a 'growth mindset' actually means", Harvard Business Review, vol. 13, pp. 213-226.

Earley, S., (2014), "The Digital Transformation: Staying Competitive", IT Professional, vol. 16 , pp. 58-60.

Esses, D., Csete, M.S. and Németh, B., (2021), "Sustainability and digital transformation in the visegrad group of central european countries", Sustainability, vol. 13, no.11, pp. 5833.

Finelli, L.A. and Narasimhan, V., (2020), "Leading a Digital Transformation in the Pharmaceutical Industry: Reimagining the Way We Work in Global Drug Development", Clinical Pharmacology and Therapeutics, vol. 108, no. 4, pp. 756-761.

Frank, A.G., Dalenogare, L.S. and Ayala, N.F., (2019), "Industry 4.0 technologies: Implementation patterns in manufacturing companies", International Journal of 
Production Economics, vol. 210, pp. 15-26.

Frick, N.R.J., Möllmann, H.L., Mirbabaie, M. and Stieglitz, S., (2021), "Driving digital transformation during a pandemic: Case study of virtual collaboration in a German hospital", JMIR Medical Informatics, vol. 9, no. 2, e25183.

Gartner., (2018), "Digital Dexterity at Work: How and why to prepare your workforce for the future of digital".

Gavin, R., Harrison, L., Plotkin, C.L., Spillecke, D. and Stanley, J., (2020), "The B2B digital inflection point: How sales have changed during COVID-19". Available at https://www.mckinsey.com/business-functions/marketing-and-sales/our-insights/theb2b-digital-inflection-point-how-sales-have-changed-during-covid-19.

Gopal, G., Suter-Crazzolara, C., Toldo, L. and Eberhardt, W., (2019), "Digital transformation in healthcare - Architectures of present and future information technologies", Clinical Chemistry and Laboratory Medicine, vol. 57, no. 3, pp. 328-335.

Guenzi, P. and Habel, J., (2020), "Mastering the Digital Transformation of Sales", California Management Review, vol. 62, no. 4, pp. 57-85.

Gurbaxani, V. and Dunkle, D., (2019), "Gearing up for successful digital transformation", MIS Quarterly Executive, vol. 18, no. 3, pp. 209-220.

Hadjielias, E., Discua Cruz, A., Dada, L. and Christofi, M., (2021), "How do digital innovation teams function?: Understanding the team cognition-team process nexus within the context of digital transformation", Journal of Business Research, vol. 122, pp. 373386.

Haggerty, E., (2017), "Healthcare and digital transformation”, Network Security, vol. 2017, no. 8, pp. 7-11.

Hanelt, A., Gregory, R.W. and Hildebrandt, B., (2015), "Digital Transformation of Primarily Physical Industries-Exploring the Impact of Digital Trends on Business Models of Automobile Manufacturers", Wirtschaftsinformatik, vol. 88, no.3-5, pp. 1313-1327.

Hartl, E. and Hess, T., (2017), "The Role of Cultural Values for Digital Transformation: Insights from a Delphi Study", in Proceedings of the 23rd Americas Conference on Information Systems, Boston, USA, pp.1364-1374.

Horlacher, A. and Hess, T., (2016), "What Does a Chief Digital Officer Do? Managerial Tasks and Roles of a New C-Level Position in the Context of Digital Transformation", in Proceedings of the 49th Hawaii International Conference on System Sciences, Hawaii, pp. 5126-5135.

Jackson, N.C. and Dunn-Jensen, L.M., (2021), "Leadership succession planning for today's digital transformation economy: Key factors to build for competency and innovation", Business Horizons, vol. 64, no. 2, pp. 273-284.

Kane, G.C., Phillips, A.N., Copulsky, J.R. and Andrus, A.G., (2019), The Technology Fallacy: How People Are the Real Key to Digital Transformation, The MIT Press, Cambridge.

Khan, Md.M.R. and Basak, K., (2021), "Shifts in pharma-marketing trends in post COVID-19 era", International Journal of Multidisciplinary: Applied Business and Education Research, vol. 2, no. 2, pp. 108-114.

Kim, R.Y., (2020), “The impact of COVID-19 on consumers: Preparing for digital sales”, IEEE Engineering Management Review, vol. 48, no. 3, pp.212-218.

Kraus, S., Schiavone, F., Pluzhnikova, A. and Invernizzi, A.C., (2021), "Digital transformation in healthcare: Analyzing the current state-of-research", Journal of Business Research, vol. 123, pp. 557-567.

Laurenza, E., Quintano, M., Schiavone, F. and Vrontis, D., (2018), "The effect of digital technologies adoption in healthcare industry: A case based analysis", Business Process Management Journal, vol. 24, no. 5, pp. 1124-1144.

Li, F. , "The digital transformation of business models in the creative industries: A holistic framework and emerging trends", Technovation, vol. 92-93, pp. 102012.

Li, L., Su, F., Zhang, W. and Mao, J.Y., (2018), "Digital transformation by SME entrepreneurs: A capability perspective", Information Systems Journal, vol. 28, no. 6, pp. 1129-1157.

Ministry of Health, Labour and Welfare, (2018), "Guidelines for Sales Information Provision 
Activities

for

Drugs".

Available

at

https://www.mhlw.go.jp/content/11120000/000501927.pdf.

Myers, M.D. and Newman, M., (2007), "The qualitative interview in IS research: Examining the craft", Information and Organization, vol. 17, no. 1, pp. 2-26.

Nagatani, T., Raviscioni, M. and Sugahara, A., (2018), "Change in the Japanese pharmaceutical market: Cradle of innovation or grave of corporate profits?". Available at https://www.mckinsey.com/industries/life-sciences/our-insights/change-in-thejapanese-pharmaceutical-market-cradle-of-innovation-or-grave-of-corporate-profits.

Ngamvichaikit, A., (2021), "Leveraging Design Thinking for Pharmaceutical Digital Marketing", Asian Journal of Business Research, vol. 11, no. 1.

du Plessis, D., Sake, J.K., Halling, K., Morgan, J., Georgieva, A. and Bertelsen, N., (2017), "Patient centricity and pharmaceutical companies: is it feasible?", Therapeutic innovation \& regulatory science, vol. 51, no. 4, pp. 460-467.

Remane, G., Hanelt, A., Wiesböck, F. and Kolbe, L., (2017), "Digital maturity in traditional industries-an exploratory analysis", in Proceedings of the 25th European Conference on Information Systems, Guimarães, Portugal.

Savastano, M., Amendola, C., Bellini, F. and D'Ascenzo, F., (2019), "Contextual Impacts on Industrial Processes Brought by the Digital Transformation of Manufacturing: A Systematic Review", Sustainability, vol.11, no. 3, pp. 891-929.

Schein, E.H., (2016), Organizational Culture and Leadership (5th Edition), Wiley.

Singh, A. and Hess, T., (2017), "How chief digital officers promote the digital transformation of their companies", MIS Quarterly Executive, vol. 16, no. 1, pp. 1-17.

Soltani Delgosha, M., Heydari, N. and Saheb, T., (2020), "The Configurational Impact of Digital Transformation on Sustainability: A Country-Level Perspective", in Proceedings of the 28th European Conference on Information Systems, Research Paper 33.

Spritzer, B., Buvat, J., Morel, V. and KVJ. S., (2017), "The Digital Talent Gap Developing Skills for Today's Digital Organizations". Available at https://www.capgemini.com/wp-content/uploads/2017/07/the_digital_talent_gap2709_0.pdf.

Umekawa, T., (2019), "As medical costs mount, Japan to weigh cost-effectiveness in setting drug prices". Available at https://www.reuters.com/article/us-japan-drugsidUSKCN1Q71ZG.

Vial, G., (2019), "Understanding Digital Transformation: A Review and a Research Agenda", Journal of Strategic Information Systems, vol. 28, no. 2, pp. 118-144.

Wedell, A. and Hempeck, D., (1987), "Sales Force Automation-Here and Now", Journal of Personal Selling \& Sales Management, vol. 7, no. 2, pp. 11-16.

Zhao, Z., (2018), "Suning Intelligent Retail Practitioner from Digital to Intelligent", Business School, Vol. 8, pp. 91-92. 